\title{
Fourteen years' experience with 501 subcoronary Ross procedures: Surgical details and results
}

\author{
Hans-H. Sievers, MD, Ulrich Stierle, MD, Efstratios I. Charitos, MD, Thorsten Hanke, MD, \\ Armin Gorski, MD, Martin Misfeld, MD PhD, and Matthias Bechtel, MD
}

\begin{abstract}
Objective: During the past decade the Ross procedure using the full root has become the predominant surgical technique. However, progressive autograft dilatation and eventual failure remain a concern. Here we report on the surgical techniques and results of the subcoronary technique over a 14-year period.
\end{abstract}

\begin{abstract}
Methods: A total of 501 patients (mean age, $44.9 \pm 12.9$ years; 117 female; 384 male) were operated on from June 1994 to December 2007. The follow-up database, with a completeness of $98.2 \%$, was closed on December 2008 , comprising of 2931 patient-years with a mean follow-up of $5.9 \pm 3.6$ years (range, 0.1-14.1 years).

Results: Surgical details are presented. Early and late mortality were $0.4 \%(n=2)$ and $4 \%(n=20)$, respectively, valve-related mortality was $1.2 \%(\mathrm{n}=6)$, whereas the overall survival did not differ from that of the normal population. Neurologic events occurred in 22 patients, major bleeding in 9 , autograft endocarditis in 8 , and homograft endocarditis in 10 . Freedom from autograft and homograft reoperation was $91.9 \%$ at 10 years. For the majority of patients, hemodynamics was excellent and no root dilatation was observed.
\end{abstract}

Conclusions: Midterm results after the original subcoronary Ross procedure are excellent, including normal survival and low risk of valve-related morbidity. Longer-term results are necessary for continuous judgment of the subcoronary technique. (J Thorac Cardiovasc Surg 2010;140:816-22)

Supplemental material is available online.

Video clip is available online.
The pulmonary autograft procedure for the treatment of aortic valve disease, first performed by Donald Ross ${ }^{1}$ in 1967 , is the only aortic valve replacement procedure that theoretically provides all the advantages of a viable autologous tissue valve, achieving almost physiologic aortic valve hemodynamics and motion ${ }^{2,3}$ with low incidence of macroembolism and microembolism ${ }^{3-6}$ and without the need for lifelong anticoagulation. This makes the procedure especially attractive to young patients, whose quality of life may be limited by the valve-related morbidity of mechanical substitutes and the limited durability of biological prostheses

From the University of Lübeck, Department of Cardiac and Thoracic Vascular Surgery, Lübeck, Germany.

Disclosures: None.

Clinical Trials ID: NCT 00708409.

Received for publication Aug 14, 2009; revisions received Nov 6, 2009; accepted for publication Nov 26, 2009; available ahead of print March 18, 2010.

Address for reprints: Hans-H. Sievers, MD, University of Schleswig-Holstein, Campus Lübeck, Department of Cardiac and Thoracic Vascular Surgery, Ratzeburger Allee 160, 23538 Lübeck, Germany (E-mail: sievers@medinf.mu-luebeck.de). $0022-5223 / \$ 36.00$

Copyright (C) 2010 by The American Association for Thoracic Surgery doi:10.1016/j.jtcvs.2009.11.042 in this age group. ${ }^{7}$ Since the publication of excellent results in the early and late $1990 \mathrm{~s},{ }^{4,5,8}$ a renaissance of this surgical method has been lately observed. ${ }^{3,9-12}$

Although the Ross operation was initially performed as a subcoronary transplant, ${ }^{1}$ the technical complexity of this technique made the reproduction of Ross's initial and late results ${ }^{1,5}$ with the subcoronary technique difficult. This led to the development of the total root replacement technique, in which the complete aortic root is entirely replaced by the pulmonary root. $^{4,8,13}$ This technique has received broad acceptance in $81 \%$ of patients of the International Ross Registry. ${ }^{14}$ However, concerns have surfaced lately regarding the ability of the isolated, unsupported pulmonary root to withstand the systemic circulation over time without progressive dilatation, leading to an unexpectedly increased reoperation rate 7 to 9 years after the initial operation. ${ }^{9,10,15,16}$ We have performed the Ross operation with the subcoronary technique since 1994. Here we present a detailed description of the subcoronary surgical technique and our results in 501 patients. $^{17}$

\section{PATIENTS AND METHODS}

From June 1994 through December 2007, the subcoronary Ross technique was performed in 501 consecutive patients, being $9.6 \%$ of the total number of aortic valve procedures in our center within that period. During this time period, 6 full root Ross procedures were performed (not included in this study), mainly in patients with severely malformed aortic roots, aortic roots destroyed by endocarditis, and reoperation after valve-sparing procedures and xenograft implantation. Thirty-three patients operated on with the root inclusion technique were included in this patient population. Because we did not find any difference between the root inclusion technique and the subcoronary technique in this study or in previous studies, ${ }^{3,11,15}$ we decided to include these patients in the subcoronary population. The operative 


\section{Abbreviations and Acronyms \\ $\mathrm{CI}=$ confidence interval \\ $\mathrm{LOR}=$ linearized occurrence rate}

indications were in line with American Heart Association/American College of Cardiology guidelines. ${ }^{17}$ The presence of markedly reduced left ventricular function, extensive coronary artery disease, connective tissue or active rheumatic disorders, severe deformation of the aortic root anatomy, or structural defects of the pulmonary valve, as well as intractable systemic hypertension, were considered contraindications for the Ross procedure. It is generally our philosophy that the Ross procedure is an extraordinary aortic valve replacement technique besides the commonly used alternatives and should not be performed if there are any doubts about the anatomy, the technical feasibility, or the attitude of the patient, the surgeon, or the cardiologist. Demographics and valve-related preoperative parameters are presented in Table 1. Early after the operation, antithrombotic treatment was initiated with aspirin $100 \mathrm{mg}$ per day and low molecular weight heparin for 1 week. Afterward, aspirin $100 \mathrm{mg}$ per day was maintained for 3 months.

\section{Surgical Technique}

The surgical technique evolved mainly over the first 5 years, thereafter being by and large standardized (see Video 1). Nevertheless, increasing experience will lead to further modifications. Standard cardiopulmonary bypass with moderate systemic hypothermia was used. In the first years crystalloid cardioplegia was applied and later cold blood cardioplegia at 20-minute intervals. A detailed description of the surgical technique including 9 figures (Figures E1-E9) and a video is provided in the online E-Appendix.

\section{Follow-up}

Follow-up visits were performed prospectively on an outpatient basis 1, 3, 6 , and 12 months after the operation and annually thereafter by clinical evaluation and serial standardized echocardiography. ${ }^{11}$ All perioperative and postoperative events were defined according to the latest guidelines (2008) for reporting mortality and morbidity after cardiac valve interventions. ${ }^{17}$ Details of the echocardiographic evaluation have been reported previously. ${ }^{11,18,19}$ The study database was frozen on December 31, 2008. Follow-up was $98.2 \%$ complete at this time. The mean follow-up duration was $5.9 \pm 3.6$ years (range, 0.01-14.1 years) with a cumulative follow-up of 2931 patient-years.

\section{Statistical Analysis}

Continuous data were expressed as mean $\pm \mathrm{SD}$. Categorical variables were presented as absolute numbers and percentages. Estimation of longterm survival, freedom from morbid events, and valve function was made by the Kaplan-Meier method with truncation of the data at 12 years (when only $10 \%$ of patients remained at risk) so as to warrant statistical accuracy and sound conclusions. The survival time of each patient started at the time of surgery and ended at death (event) or at last follow-up (censoring). The long-term survival characteristics of the patient cohort were compared with the survival probabilities of the age- and gender-matched general population obtained from German Life Tables 2004/2006 (www.destatis.de). The analysis of event-free rates started at the time of operation and ended at the time of an event (eg, reoperation, thromboembolism, bleeding) or last follow-up or death (censoring). Statistics for patients with incomplete follow-up investigations were censored at the time of their last inquiry.

The SPSS 13.0 for Windows statistical software (SPSS, Inc, Chicago, Ill) was used for all analyses. The authors had full access to the data and take responsibility for their integrity. Informed consent was obtained from all patients preoperatively and before each follow-up visit. The local ethics committee approved the present study (Clinical Trials ID: NCT 00708409).

\section{RESULTS \\ Mortality}

Early mortality. All-cause early ( $<30$ days) mortality was $0.4 \%$ ( $n=2$, owing to refractory ventricular arrhythmias 3 days postoperatively and to a thromboembolic occlusion of the left main coronary artery 7 days after valve replacement for infective endocarditis). The autograft function was excellent. No early mortalities occurred in the following 291 procedures.

Valve-related late mortality. Valve-related mortality was $1.2 \%$ (6 patients, linearized occurrence rate [LOR] $0.20 \%$ / patient-year): 1 patient with coronary embolism, 1 with refractory ventricular arrhythmias, 1 with surgically treated valve endocarditis (primary mitral valve endocarditis, with eventual involvement of the autograft and homograft), 2 sudden, unexplained deaths (last follow-up examinations revealed no valvular problems in these patients), and 1 patient with heart failure with severe regurgitation of all 4 cardiac valves.

Cardiac death. The number of deaths of cardiac etiology was 8 (LOR, 0.27\%/patient-year). Included are 6 valverelated deaths and 2 non-valve-related cardiac fatalities.

All-cause mortality. All-cause mortality, including early mortality, was $20(4.0 \%, 0.68 \% /$ patient-year $): 8$ cardiac deaths, 6 malignancies, 1 suicide, 1 multiorgan failure after noncardiac surgery, 1 renal failure, 2 bleeding events (hypertensive cerebral hemorrhage, bleeding of esophageal varices), and 1 intoxication. The cumulative overall survival compared with the expected number of deaths of the age- and gendermatched general German population is shown in Figure 1.

\section{Morbidity}

Five patients required the implantation of a permanent pacemaker in the immediate postoperative period $(\leq 14$ days postoperatively).

Structural valve deterioration. Structural valve deterioration with impact on clinical functional capacity according to the New York Heart Association was present in 8 patients. Echocardiography revealed a relevant valvular impairment in these patients (aortic regurgitation grade II or III, $\mathrm{n}=2$; increase of mean pressure gradient across the pulmonary homograft, $n=6$ ). In 6 patients a marked systolic left ventricular impairment was observed without obvious valvular dysfunction. Structural valve deterioration verified by reoperation was present in 13 patients (9 autografts, 4 homografts; see Reoperation section).

Nonstructural dysfunction. Nonstructural valve dysfunction $^{17}$ was confirmed in 2 homograft reoperations (1 patient-homograft mismatch, 1 annular ring dilatation) and 2 autograft reoperations (1 annular dilatation, 1 dilatation of the sinotubular junction).

Valve thrombosis. One patient required reoperation on the homograft 14 months after the primary procedure owing to obstruction caused by extensive leaflet-adherent thrombi in 
TABLE 1. Patient demographics and preoperative characteristics

\begin{tabular}{|c|c|c|}
\hline \multirow{2}{*}{$\begin{array}{l}\mathrm{n} \\
\text { Mean age, y (range) }\end{array}$} & \multicolumn{2}{|l|}{501} \\
\hline & \multicolumn{2}{|c|}{$44.9 \pm 12.9(13.8-70.5)$} \\
\hline$<20$ & 19 & $3.8 \%$ \\
\hline $20-40$ & 161 & $32.1 \%$ \\
\hline $41-60$ & 274 & $54.7 \%$ \\
\hline$>60$ & 47 & $9.4 \%$ \\
\hline \multicolumn{3}{|l|}{ Gender } \\
\hline Male & 384 & $76.6 \%$ \\
\hline Female & 117 & $23.4 \%$ \\
\hline \multicolumn{3}{|l|}{ NYHA } \\
\hline I & 144 & $28.7 \%$ \\
\hline II & 261 & $52.1 \%$ \\
\hline III & 93 & $18.6 \%$ \\
\hline IV & 3 & $0.6 \%$ \\
\hline \multicolumn{3}{|l|}{ Ejection fraction $(\%)$} \\
\hline$>50$ & 458 & $91.4 \%$ \\
\hline $30-50$ & 42 & $8.4 \%$ \\
\hline$<30$ & 1 & $0.2 \%$ \\
\hline Diabetes mellitus & 22 & $4.4 \%$ \\
\hline Hypertension & 168 & $33.5 \%$ \\
\hline Impaired renal function & 32 & $6.4 \%$ \\
\hline \multicolumn{3}{|l|}{ Rhythm } \\
\hline Sinus & 493 & $98.4 \%$ \\
\hline Atrial fibrillation & 7 & $1.4 \%$ \\
\hline Pacemaker & 1 & $0.2 \%$ \\
\hline \multicolumn{3}{|l|}{ Hemodynamic diagnosis } \\
\hline Stenosis & 73 & $14.6 \%$ \\
\hline Regurgitation & 148 & $29.5 \%$ \\
\hline Mixed lesion & 279 & $55.7 \%$ \\
\hline $\begin{array}{c}\text { Prosthetic valve } \\
\text { dysfunction }\end{array}$ & 1 & $0.2 \%$ \\
\hline \multicolumn{3}{|l|}{ Aortic valve morphology } \\
\hline Tricuspid & 128 & $25.5 \%$ \\
\hline Bicuspid & 344 & $68.7 \%$ \\
\hline Unicuspid & 15 & $3.0 \%$ \\
\hline Other & 14 & $2.8 \%$ \\
\hline \multicolumn{3}{|l|}{ Etiology } \\
\hline Congenital & 345 & $68.9 \%$ \\
\hline Degenerative & 184 & $36.7 \%$ \\
\hline Myxomatous & 55 & $11.0 \%$ \\
\hline Rheumatic & 6 & $1.2 \%$ \\
\hline Acute endocarditis & 25 & $5.0 \%$ \\
\hline \multicolumn{3}{|l|}{$\begin{array}{l}\text { Prior aortic valve } \\
\text { interventions }\end{array}$} \\
\hline Valve replacement & 6 & $1.2 \%$ \\
\hline Valve reconstruction & 13 & $2.6 \%$ \\
\hline
\end{tabular}

NYHA, New York Heart Association classification.

2 sinuses (despite the patient receiving aspirin). Additionally, cusp laceration was present compatible with cured endocarditis. Autograft valve thrombosis was not detected.

Embolism. Within 30 days postoperatively, stroke occurred in 1 patient (day 5; treated with aspirin and unfractionated heparin 22,500 IU/d) and a transient ischemic attack in 5 patients (all patients were treated with aspirin and unfractionated heparin 22 500,IU/d).

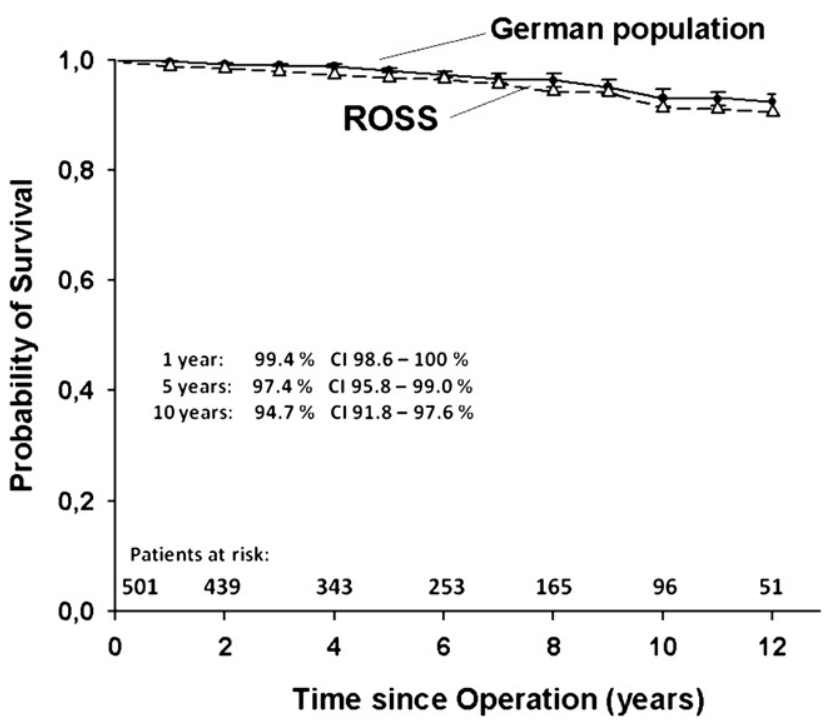

FIGURE 1. Probability of survival comparing the Ross subcoronary patient group with the age- and gender-matched general population. $C I$, $95 \%$ confidence interval.

After hospital discharge, 16 neurologic events occurred (3.2\% ; LOR, 0.55\%/patient-year; 7 strokes, 9 transient ischemic attacks). In 5 patients with stroke, new onset of atrial fibrillation (without the patient receiving anticoagulation) was present, and in 2 patients, carotid artery disease was present. Transient ischemic attacks were associated with atrial arrhythmias in 5 or carotid artery disease/thromboatheromatosis of the aortic arch in 4.

Noncerebral embolic event. There was 1 coronary embolism complicated by refractory cardiogenic shock, leading to a fatal outcome in the early postoperative period (see Mortality). In 1 patient a thromboembolic femoral artery occlusion was detected (sinus rhythm, mitral stenosis, no anticoagulation).

Bleeding. Major internal or external bleeding occurred in 9 patients $(1.8 \%$; LOR, $0.31 \%$ /patient-year). One patient with atrial fibrillation receiving oral anticoagulation therapy had a head injury causing an epidural hematoma and 1 patient without anticoagulation had a subdural hematoma after a head trauma. Additionally, 1 patient receiving anticoagulation had a subdural hematoma and another had gastrointestinal bleeding. A hematothorax developed spontaneously in a patient receiving anticoagulation. Additionally, 2 patients with hemorrhages and fatal outcome (esophageal varices, hypertensive cerebral bleeding; no anticoagulants in both patients) and 2 patients with gastrointestinal bleeding were not treated with anticoagulants. Neither fatality was related to the cardiac condition or specific cardiac drug therapy.

Antithrombotic management. At the time of the last follow-up visit, 35 patients were being treated with oral anticoagulants (phenprocoumon; target international normalized ratio, 2.5-3.0) for chronic or paroxysmal atrial fibrillation $(n=26)$, embolic events of vascular or cardiac origin 
$(\mathrm{n}=3)$, deep vein thrombosis $(\mathrm{n}=3)$, pulmonary embolism $(\mathrm{n}=2)$, and vascular surgery for chronic occlusive peripheral artery disease $(n=1)$. Antiplatelet drug therapy (100 mg aspirin daily) was used in all patients with coronary artery disease or peripheral vascular disease $(n=33)$. For nonvalvular indications, $100 \mathrm{mg}$ aspirin per day was used in 16 patients.

Composite thrombosis, embolism, and bleeding. A total of 34 patients had the composite end point of thrombosis, embolism, and bleeding (6.8\%; LOR, 1.16\%/patient-year). Operated valve endocarditis. No early endocarditis occurred ( $<30$ days). Late autograft endocarditis with severe aortic regurgitation occurred in 5 patients $(1.0 \%$; LOR, $0.17 \%$ /patient-year): acute in 1 , subacute in 2 , and cured in 2. In 2 patients a mechanical prosthesis was implanted, and in another 3 a bioprosthesis. In 1 patient with additional infective endocarditis of the homograft, the conduit was also replaced by another homograft.

Homograft endocarditis occurred in 6 patients $(1.2 \%$; LOR, $0.20 \%$ /patient-year): 3 with acute endocarditis (1 patient with autograft and homograft endocarditis), 1 with subacute endocarditis, and 2 patients with valve destruction present after cured infective endocarditis. In 1 patient recurrent homograft endocarditis had to be treated with a second reoperation. In all cases the infected homograft was replaced by another homograft. Recurrent homograft endocarditis was treated with a stentless bioprosthesis.

One patient (not included in the above numbers) with primary mitral valve endocarditis after mitral valve replacement with a bioprosthesis had trivalvular endocarditis with involvement of the mitral bioprosthesis, the autograft, and the homograft. He died 1 week after mitral valve replacement in a septic shock state.

Medically treated valve endocarditis. Conservative medical treatment of autograft endocarditis was successful in 3 and homograft endocarditis in 4 patients $(1.4 \%$; LOR, $0.24 \%$ /patient-year).

The LOR for all operated and medically treated endocarditis events was $0.65 \% /$ patient-year

Reoperation. Twenty-six reoperations on 28 Ross-related valves (pulmonary autograft, pulmonary homograft) were required in 23 patients $(4.6 \%$; $0.78 \%$ /patient-year); the time interval between the initial procedure and the reoperation was $4.82 \pm 4.00$ years (range, $0.01-11.7$ years; median, 2.85 years). Thirteen interventions in 10 patients ( 1 patient had repeated interventions owing to recurrent infective endocarditis) were performed solely on the pulmonary conduit ( $2.6 \%$; LOR, $0.44 \% /$ patient-year). Twelve patients underwent reinterventions on the autograft only $(2.4 \%$; LOR, $0.41 \% /$ patient-year) and 3 patients on both the autograft and homograft $(0.6 \%$; LOR, $0.10 \%$ /patient year).

Indications for 15 autograft reinterventions (including interventions on the autograft and homograft in 3 patients) included structural valve failure with pure aortic regurgitation in 10 patients as well as aortic valve endocarditis in 5 patients ( 2 acute interventions for annular abscess without regurgitation, 1 subacute, and 2 in patients with leaflet perforation and moderate-to-severe aortic regurgitation who were cured). Cusp prolapse (1 patient with acute endocarditis) was identified in 7 of 15 autograft reoperations (2/7 with concomitant annulus dilatation) and cusp perforations (1 patient with endocarditis) was identified in 3 reoperations. No reoperation owing to dilatation of the ascending aorta was observed. There was no correlation between autograft reoperation and valve morphologic features (bicuspid vs tricuspid aortic valve; $P=.3$ ). The autograft reoperation procedures were performed from 0.01 to 11.7 years (mean, $5.31 \pm 4.25$ years; median, 6.8 years) after the initial Ross operation. In 7 patients a mechanical valve, in 6 a bioprosthesis, and in 1 a homograft was implanted; in 1 patient an autograft reconstruction was performed. Freedom from reoperation on the autograft is displayed in Figure 2.

Among the 13 reinterventions on the pulmonary homograft (including 3 patients with replacement of the autograft and homograft and 1 patient with 3 reinterventions), 4 showed structural valve failure (in 4 pulmonary regurgitation grade III, in 1 pulmonary stenosis), 2 had nonstructural valve deterioration (patient-homograft mismatch in 1, annular dilatation in 1), and 7 had acute or cured infective endocarditis ( 2 with pure stenosis and 5 with pure regurgitation, with grade III in 4 and grade IV in 1). The homograft reoperation procedures were performed from 1.1 to 11.7 years (mean, $4.15 \pm 3.73$ years; median, 2.2 years) after the initial Ross operation. On 12 occasions another homograft was inserted; 1 patient with repeated homograft stenosis received a Shelhigh bioprosthesis (Shelhigh, Inc, Union, NJ) that degenerated within months and was replaced thereafter with

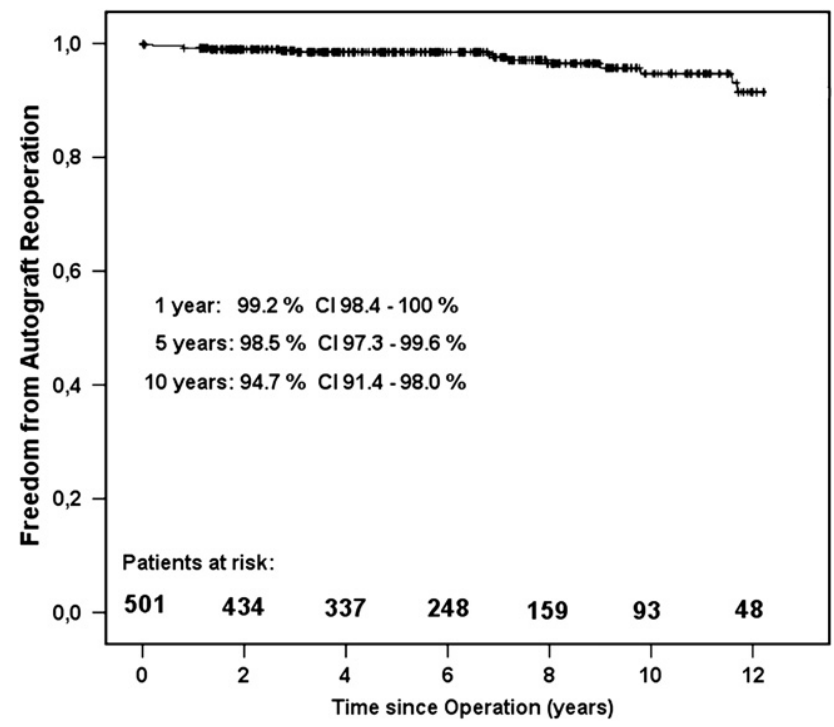

FIGURE 2. Freedom from autograft reoperation. $C I$, 95\% confidence interval. 
a Carbomedics artificial valve (Carbomedics, Inc, Austin, Tex). No transcutaneous homograft procedures were performed. Freedom from reoperation on the homograft is displayed in Figure 3. Freedom from autograft and homograft reoperation is displayed in Figure 4. All patients survived the reoperation on Ross-related valves and were alive at the date of the last follow-up inquiry.

Major adverse valve-related events. Overall freedom from any major valve-related event (all valve-related mortality; valve-related morbidity: structural valve deterioration, nonstructural valve dysfunction, thrombosis, bleeding, embolism, neurologic events including transient ischemic attacks, endocarditis, reintervention; and need for pacemaker implantation within 14 days after operation ${ }^{17}$ ) was $95.8 \%$ at 1 year $(95 \%$ confidence interval [CI], 94.0\%$97.6 \%), 90.1 \%$ at 5 years $(95 \% \mathrm{CI}, 87.4 \%-92.8 \%)$, and $81.8 \%$ at 10 years $(95 \% \mathrm{CI}, 76.9 \%-86.7 \%)$. The freedom from each of the aforementioned events at 10 years is displayed in Table 2.

Functional and echocardiographic status at last followup. Table 3 shows the functional capacity according to the New York Heart Association classification and the echocardiographic characteristics of the autograft and homograft at the last follow-up visit. At 5 years postoperatively, freedom from aortic insufficiency of grade II or more, pulmonary insufficiency of grade II or more, and homograft stenosis with a mean gradient of $25 \mathrm{~mm} \mathrm{Hg}$ or more was 94.6\% (CI, 92.2\%-99.9\%), 94.6\% (CI, 92.4\%-100\%), and $95.2 \%$ (CI, 93.0\%-100\%), respectively, and at 10 years postoperatively $85.2 \%$ (CI, $80.3 \%-100 \%$ ), $85.5 \%$ (CI, $81.0 \%-100 \%$ ), and $89.9 \%$ (CI, $86.0 \%-100 \%$ ), respectively. It must be stressed that the patients undergoing reoperation, with their hemodynamics at the time of the reoperation, are included in the aforementioned numbers.

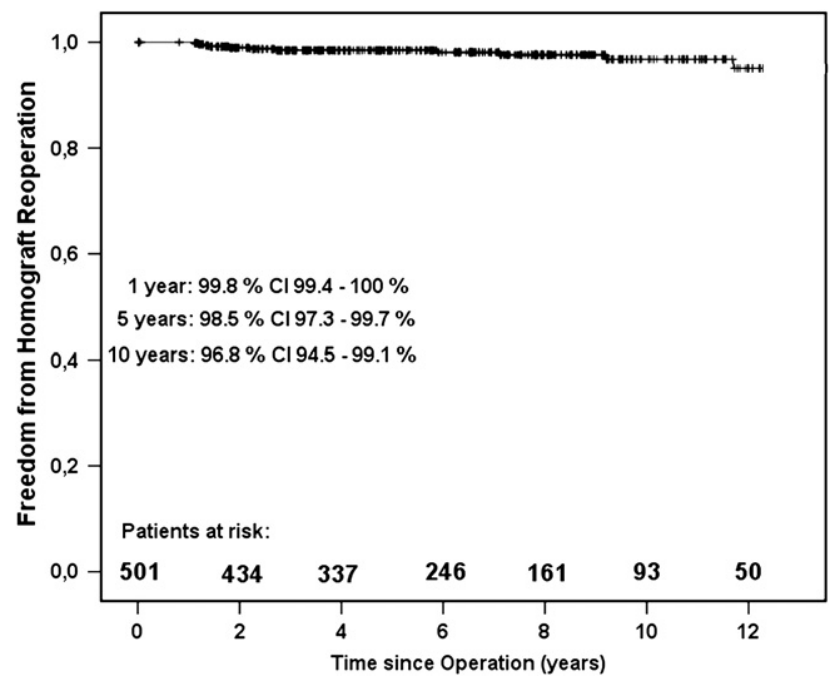

FIGURE 3. Freedom from homograft reoperation, $C I, 95 \%$ confidence interval.

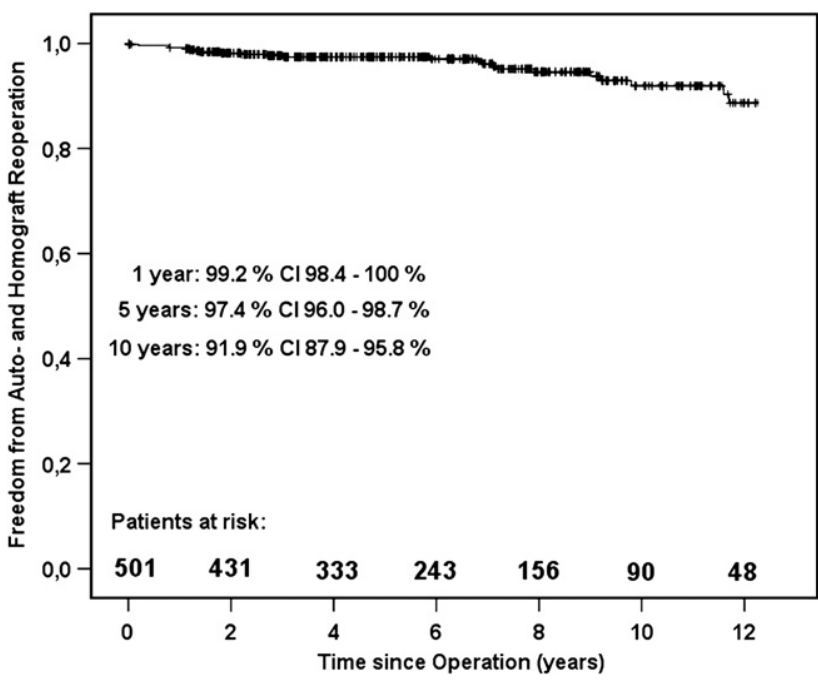

FIGURE 4. Freedom from autograft and homograft reoperation. $C I, 95 \%$ confidence interval.

Patients with more than 10 years of follow-up. There were 105 patients with more than 10 years of follow-up. Of these patients, $5.3 \%$ had reoperations on the autograft and $3.8 \%$ on the homograft compared with $2.3 \%$ and $1.8 \%$ of patients with follow-up less than 10 years, respectively. The proportion of patients with aortic insufficiency of grade 2 or more was $8.6 \%$ in patients with more than 10 years of follow-up and $3.5 \%$ for those with less than 10 years of follow-up.

\section{DISCUSSION}

This study provides some evidence that the life expectancy of patients having the Ross operation is comparable with that of the normal population, at least in the first decade after the operation. This is astonishing to some extent inasmuch as the patients had significant valvular disease before the operation that may per se have a limiting effect on survival owing to disease-related structural alterations within the myocardium and connective tissue. However, patient selection by excluding those patients with severe heart failure, as well as the excellent postoperative hemodynamics with almost normal pressure gradients across the autograft and in most cases negligible regurgitation in conjunction with the low risk of valve-related extracardiac fatal events and the close regular follow-up, may have a protective effect on patient survival.

In the full root technique, the adverse remodeling of the pulmonary root leads to progressive dilatation and aortic valve regurgitation, eventually mandating a reoperation in some patients. The incidence of reoperations increases 7 to 8 years after the initial operation. ${ }^{9,10,15,16}$ In the present series, reoperations on the autograft were related to cusp prolapse and not to autograft dilatation.

The second reason for reoperations on the autograft and homograft was the occurrence of infective endocarditis. 
TABLE 2. Freedom from death and other morbid events at 10 years

\begin{tabular}{lcc}
\hline \multicolumn{1}{c}{ Event } & Freedom (\%) & $\mathbf{9 5 \%}$ CI \\
\hline Death & 94.7 & $91.8-97.6$ \\
SVD, nSVD with AG or HG reoperation & 91.9 & $87.9-95.8$ \\
Endocarditis & 94.2 & $91.1-100$ \\
Thromboembolism (including TIAs) & 95.1 & $92.9-100$ \\
Thromboembolism (excuding. TIAs) & 97.5 & $95.9-100$ \\
Major bleeding & 97.0 & $94.5-100$ \\
\hline
\end{tabular}

$C I$, Confidence interval; $S V D$, structural valve deterioration; $n S V D$, nonstructural valve deterioration; $A G$, autograft; $H G$, homograft; TIAs, transient ischemic attacks.

Whether this can be more favorably addressed with the appropriate use of endocarditis prophylaxis remains speculative. On the other hand, homograft degeneration with time remains an issue; however, novel decellularization protocols reducing the immunogenicity of homografts, with the potential to repopulate them with autologous cells, are promising. $^{20}$ Although decellularized xenografts are reported to yield excellent results in the right ventricular outflow tract, ${ }^{21}$ our own experience with decellularized homografts is limited and does not support these promising reports. ${ }^{22}$ This may be related to the different decellularization protocols and the fact that the allografts used in our study were additionally cryopreserved, which itself causes serious alterations to the leaflet tissue. ${ }^{23}$

Taken together, the risk of reoperation is a weak point in the Ross procedure. Although this risk is low $(0.78 \%$ / patient-year) for the observed time period of 0.1 to 14.1 years (mean, $5.9 \pm 3.6$ years), it remains a matter of concern. Seven of our 501 patients have borderline hemodynamics (especially mean homograft gradients $>25 \mathrm{~mm} \mathrm{Hg}$ ) and may become candidates for possible reoperations in the future. Transfemoral approaches for pulmonary valve replacement in case of homograft failure can potentially reduce the need for conventional reoperations. ${ }^{24}$ Interestingly, there is no exponential increase in reoperations in the longer term after 7 to 8 years, even in young patients, in contrast to reports with the full root technique. $9,10,15,16$ However, the mean follow-up duration of our patients was 6 years, and only longer-term results can give more definite information on this subject. Although reoperation is a devastating problem for the patient, there was no fatal outcome or increased morbidity in our group during reoperations on the Ross-related valves.

Morbidity is low and bleeding complications are most probably related to anticoagulant medication prescribed not for the Ross procedure itself but for other coexisting diseases, such as atrial fibrillation. If this was taken into account in the reporting guidelines, the incidence of strictly valve-related morbidity after the Ross procedure would be even lower than reported here, something that also holds true for bioprostheses.

Furthermore, quality of life is not considered, either in the guidelines or in this article. There are, however, aspects of quality of life, as measured by the 36 item Short-Form Health Survey, that are advantageous in the Ross procedure ${ }^{25}$ com-
TABLE 3. Functional and echocardiographic outcome at last followup visit

\begin{tabular}{|c|c|c|c|}
\hline \multicolumn{4}{|c|}{ NYHA class } \\
\hline I & \multicolumn{3}{|l|}{$449(93.9 \%)$} \\
\hline II & \multicolumn{3}{|l|}{$27(5.6 \%)$} \\
\hline III & \multicolumn{3}{|l|}{$2(0.4 \%)$} \\
\hline IV & \multicolumn{3}{|l|}{0} \\
\hline \multicolumn{4}{|c|}{$\begin{array}{l}0 \\
\text { Echocardiographic results }\end{array}$} \\
\hline \multicolumn{4}{|c|}{ Echocardiographic results } \\
\hline \multicolumn{2}{|c|}{$A G$ gradient, mean $(\mathrm{mm} \mathrm{Hg})$} & \multicolumn{2}{|c|}{ AG regurgitation (grade) } \\
\hline$<5$ & $338(73.0 \%)$ & None & $179(38.7 \%)$ \\
\hline $5-10$ & $119(25.7 \%)$ & Trivial & $166(35.9 \%)$ \\
\hline$>10$ & 0 & $1 / 4$ & $88(19.0 \%)$ \\
\hline \multirow[t]{4}{*}{ Unknown } & \multirow[t]{4}{*}{$6(1.3 \%)$} & $2 / 4$ & $24(5.2 \%)$ \\
\hline & & $3 / 4$ & $3(0.6 \%)$ \\
\hline & & $4 / 4$ & 0 \\
\hline & & Unknown & $2(0.4 \%)$ \\
\hline \multicolumn{2}{|c|}{$H G$ gradient mean $(\mathrm{mm} \mathrm{Hg})$} & \multicolumn{2}{|c|}{$H G$ regurgitation (grade) } \\
\hline$<5$ & $111(23.8 \%)$ & None & $215(46.0 \%)$ \\
\hline $5-10$ & $240(51.4 \%)$ & Trivial & $136(29.1 \%)$ \\
\hline $11-15$ & $66(14.1 \%)$ & $1 / 4$ & $86(18.4 \%)$ \\
\hline $16-20$ & $25(5.4 \%)$ & $2 / 4$ & $25(5.4 \%)$ \\
\hline $21-25$ & $12(2.6 \%)$ & $3 / 4$ & $2(0.4 \%)$ \\
\hline$>25$ & $6(1.3 \%)$ & $4 / 4$ & 0 \\
\hline Unknown & $7(1.5 \%)$ & Unknown & $3(0.6 \%)$ \\
\hline
\end{tabular}

Deceased $(\mathrm{n}=20)$ and patients lost-to-follow-up $(\mathrm{n}=3)$ are excluded. Reoperated valves are excluded from the corresponding valve function sections.

pared with mechanical valves. These aspects are in addition to freedom from noise disturbance ${ }^{26}$ and lifelong anticoagulation as well as unrestricted daily activities (sports, profession, and nutrition). Female patients of child-bearing age benefit from freedom from anticoagulation after the Ross procedure; for example, 8 female patients had uncomplicated delivery of 12 children in our patient group. Mechanical valve-related microembolism ${ }^{6}$ with the potential for continuous cognitive impairment ${ }^{27}$ is not considered in the new guidelines. Also not taken into account are hemodynamics like the near normal transvalvular pressure gradients at rest and exercise in Ross patients, ${ }^{28}$ left ventricular mass regression, ${ }^{18}$ and near normal flow turbulence characteristic downstream from the autograft, ${ }^{29}$ in contrast to the altered coronary flow reserve in patients with mechanical valves. ${ }^{30}$ Besides these objective parameters, how can we grade and evaluate the fear of a patient for adverse events after the Ross operation (mainly the need for reoperation), which does not occur suddenly and has a low risk of mortality and morbidity? On the other hand, there is the fear of sudden unexpected major events with a mechanical valve, mainly involving extracardiac organs, with the potential of lifelong disability (eg, stroke). How should we objectively measure the shortcomings of anticoagulation-related minor problems, such as troubles and uncertainties during dental procedures, nose bleeding, and minor and major accidents?

In conclusion, our experience with 501 subcoronary Ross operations shows excellent clinical and hemodynamic results 
with normal survival and low valve-related morbidity for the observed time period of 0.1 to 14.1 years (mean, $5.9 \pm 3.6$ years). The selection bias makes the comparison of the Ross operation with mechanical valves or bioprostheses difficult. The use of randomization or propensity scoring techniques seems indispensible for comparison of the Ross operation with other alternatives. Although a certain risk for reoperation does exist with the subcoronary technique, for the observed time period of 0.1 to 14.1 years (mean, $5.9 \pm 3.6$ years) postoperatively this risk remains low and no exponential increase of the reoperation rate with time is observed, in contrast to the full root technique. ${ }^{9,10,15,16}$ In general, candidates for aortic valve replacement have to be thoroughly informed about the full spectrum of the aforementioned aspects. That holds true for the Ross operation and also for all other alternatives. Decision-making is difficult and is related not only to the valve substitute per se but also to the attitude of the patient, the surgeon/ cardiologist, and the technical details and postoperative care. All substitutes have their intrinsic advantages and disadvantages; we are far from an ideal solution. All efforts have to be concentrated on improving implants and techniques. For the final judgment of the subcoronary method reported in this article, there is no doubt that longer-term follow-up studies are needed.

\section{References}

1. Ross DN. Replacement of aortic and mitral valves with a pulmonary autograft. Lancet. 1967;2:956-8.

2. Yacoub MH, Kilner PJ, Birks EJ, Misfeld M. The aortic outflow and root: a tale of dynamism and crosstalk. Ann Thorac Surg. 1999;68(3 Suppl):S37-43.

3. Hanke T, Stierle U, Boehm JO, Botha CA, Matthias Bechtel JF, Erasmi A, et al. Autograft regurgitation and aortic root dimensions after the Ross procedure: the German Ross Registry experience. Circulation. 2007;116(11 Suppl):I251-8.

4. Kouchoukos NT, Davila-Roman VG, Spray TL, Murphy SF, Perrillo JB. Replacement of the aortic root with a pulmonary autograft in children and young adults with aortic-valve disease. N Engl J Med. 1994;330:1-6.

5. Chambers JC, Somerville J, Stone S, Ross DN. Pulmonary autograft procedure for aortic valve disease: long-term results of the pioneer series. Circulation. 1997;96: 2206-14.

6. Notzold A, Droste DW, Hagedorn G, Berndt S, Kaps M, Graf B, et al. Circulating microemboli in patients after aortic valve replacement with pulmonary autografts and mechanical valve prostheses. Circulation. 1997;96:1843-6.

7. Rahimtoola SH. Choice of prosthetic heart valve for adult patients. J Am Coll Cardiol. 2003;41:893-904.

8. Elkins RC, Lane MM, McCue C, Ward KE. Pulmonary autograft root replacement: mid-term results. J Heart Valve Dis. 1999;8:499-503; discussion 503-6.

9. Elkins RC, Thompson DM, Lane MM, Elkins CC, Peyton MD. Ross operation: 16-year experience. J Thorac Cardiovasc Surg. 2008;136:623-30. e1-5.

10. Takkenberg JJ, Klieverik LM, Schoof PH, van Suylen RJ, van Herwerden LA, Zondervan PE, et al. The Ross procedure: a systematic review and meta-analysis. Circulation. 2009;119:222-8.
11. Sievers HH, Hanke T, Stierle U, Bechtel MF, Graf B, Robinson DR, et al. A critical reappraisal of the Ross operation: renaissance of the subcoronary implantation technique? Circulation. 2006;114(1 Suppl):I504-11.

12. da Costa FD, Santos LR, Collatusso C, Matsuda CN, Lopes SA, Cauduro S, et al. Thirteen years' experience with the Ross Operation. J Heart Valve Dis. 2009;18: 84-94.

13. Stelzer P, Jones DJ, Elkins RC. Aortic root replacement with pulmonary autograft. Circulation. 1989;80(5 Pt 2):III209-13.

14. Botha CA. The Ross operation: utilization of the patient's own pulmonary valve as a replacement device for the diseased aortic valve. Expert Rev Cardiovasc Ther. 2005;3:1017-26.

15. Charitos EI, Hanke T, Stierle U, Robinson DR, Bogers AJ, Hemmer W, et al. Autograft reinforcement to preserve autograft function after the Ross procedure: a report from the German-Dutch Ross registry. Circulation. 2009;120(11 Suppl): S146-54.

16. Kouchoukos NT, Masetti P, Nickerson NJ, Castner CF, Shannon WD, DavilaRoman VG. The Ross procedure: long-term clinical and echocardiographic follow-up. Ann Thorac Surg. 2004;78:773-81; discussion 781.

17. Akins CW, Miller DC, Turina MI, Kouchoukos NT, Blackstone EH, Grunkemeier GL, et al. Guidelines for reporting mortality and morbidity after cardiac valve interventions. J Thorac Cardiovasc Surg. 2008;135:732-8.

18. Duebener LF, Stierle U, Erasmi A, Bechtel MF, Zurakowski D, Bohm JO, et al. Ross procedure and left ventricular mass regression. Circulation. 2005;112(9 Suppl):I415-22.

19. Perry GJ, Helmcke F, Nanda NC, Byard C, Soto B. Evaluation of aortic insufficiency by Doppler color flow mapping. J Am Coll Cardiol. 1987;9:952-9.

20. Cebotari S, Lichtenberg A, Tudorache I, Hilfiker A, Mertsching H, Leyh R, et al. Clinical application of tissue engineered human heart valves using autologous progenitor cells. Circulation. 2006;114(1 Suppl):I132-7.

21. Dohmen PM, Lembcke A, Holinski S, Kivelitz D, Braun JP, Pruss A, et al. Midterm clinical results using a tissue-engineered pulmonary valve to reconstruct the right ventricular outflow tract during the Ross procedure. Ann Thorac Surg. 2007; 84:729-36.

22. Bechtel JF, Stierle U, Sievers HH. Fifty-two months' mean follow up of decellularized SynerGraft-treated pulmonary valve allografts. J Heart Valve Dis. 2008; 17:98-104; discussion 104.

23. Schenke-Layland K, Madershahian N, Riemann I, Starcher B, Halbhuber KJ, Konig K, et al. Impact of cryopreservation on extracellular matrix structures of heart valve leaflets. Ann Thorac Surg. 2006;81:918-26.

24. Nordmeyer J, Lurz P, Tsang VT, Coats L, Walker F, Taylor AM, et al. Effective transcatheter valve implantation after pulmonary homograft failure: a new perspective on the Ross operation. J Thorac Cardiovasc Surg. 2009;138:84-8.

25. Notzold A, Huppe M, Schmidtke C, Blomer P, Uhlig T, Sievers HH. Quality of life in aortic valve replacement: pulmonary autografts versus mechanical prostheses. J Am Coll Cardiol. 2001;37:1963-6.

26. Blome-Eberwein SA, Mrowinski D, Hofmeister J, Hetzer R. Impact of mechanical heart valve prosthesis sound on patients' quality of life. Ann Thorac Surg. 1996;61:594-602.

27. Uekermann J, Suchan B, Daum I, Kseibi S, Perthel M, Laas J. Neuropsychological deficits after mechanical aortic valve replacement. J Heart Valve Dis. 2005; $14: 338-43$

28. Sievers HH, Schmidtke C, Graf B. Hemodynamics of semilunar valves at rest and exercise at an average of more than two years after the Ross procedure. $J$ Heart Valve Dis. 2001;10:166-9; discussion 169-70.

29. Steinbruchel DA, Hasenkam JM, Nygaard H, Riis CM, Sievers HH. Blood velocity patterns after aortic valve replacement with a pulmonary autograft. Eur J Cardiothorac Surg. 1997;12:873-5.

30. Nemes A, Forster T, Geleijnse ML, ten Cate FJ, Csanady M. The effect of aortic valve replacement on coronary flow reserve. J Thorac Cardiovasc Surg. 2006; 132:726-7. author reply 727-8. 


\section{E-APPENDIX}

\section{Surgical Technique}

1. Aortotomy and inspection of the aortic valve. The aortotomy is S-shaped, reaching into the noncoronary sinus, especially in patients with bicuspid aortic valves, because in these cases the noncoronary sinus is usually enlarged and can be adjusted by later aortotomy closure to the size of the autograft. If the sinotubular junction or the ascending aorta is larger than $50 \mathrm{~mm}$, the ascending aorta is replaced by a supracommissural tube graft. Extensive and meticulous decalcification is necessary. The root anatomy of a tricuspid valve provides excellent conditions for the autograft implantation; bicuspid aortic valves, types I and II, ${ }^{\mathrm{E} 1}$ have favorable root anatomy, whereas a subcoronary Ross procedure in a root of a bicuspid aortic valve type 0 is challenging and, in view of alternative substitutes, questionable. Hegar dilators are used for measurement of the size of the root. The sinotubular junction should be at least the same size as the tailored annulus (see later); some millimeters larger is of no concern, because resistance against dilatation-associated regurgitation is well preserved in autografts. ${ }^{\mathrm{E} 2} \mathrm{~A}$ sinotubular junction diameter after implantation smaller than that of the autograft in the pulmonary position is potentially a risk factor for cusp prolapse-induced aortic insufficiency. This can be prevented by a small pericardial patch, normally $1 \mathrm{~cm}$ in width in the aortotomy suture line if necessary, or by not incising the noncoronary sinus during aortotomy. If the maximal diameter of the sinotubular junction or ascending aorta is larger than $50 \mathrm{~mm}$, the ascending aorta is replaced by a supracommissural tube graft.

2. Excision of the pulmonary autograft. The trunk of the main pulmonary artery is incised anteriorly, half circumferentially and $0.5 \mathrm{~cm}$ distal to the anterior commissure, allowing for inspection of the valve. Large fenestrations, thickened and retracted leaflet tissue, and quadricuspid valves are considered contraindications. Only slight disproportions of leaflets and sinuses are accepted and adjusted by adequate positioning of the autograft in the aortic root. The pulmonary trunk is transected completely and tilted anteriorly to dissect the plane between the adventitia and the pulmonary trunk posteriorly. Care must be taken to stay close to the autograft. Usually an Overholt forceps placed through the pulmonary valve into the right ventricular outflow tract, indicating a level of $2 \mathrm{~mm}$ beneath the pulmonary annulus, is used to determine the right ventricular cross-sectional incision line. This incision is continued close to the semilunar attachment of the leaflets, trying to find a dissection plane posteriorly between the valve and right ventricular muscle. Special care has to be taken at the left lateral aspect of this dissection plane, where a typical right ventricular outflow tract muscle bundle indicates the position of the first septal branch (Merrick AF, Yacoub MH, Ho SY, Anderson RH. Anatomy of the muscular subpulmonary infundibulum with regard to the Ross procedure. Ann Thorac Surg. 2000;69:556-61) (Figure E1). The dissection at this area has to be kept very close to the pulmonary annulus, leaving only a small amount of muscle at the autograft. At this stage, there is a risk that the dissection level is too deep, causing problems with the coronary septal branches. After excision of the autograft, left coronary artery cardioplegia is given to identify and treat bleeding sites. The autograft is trimmed, leaving only a $1-$ to $2-\mathrm{mm}$ rim of muscular tissue while indicating the midpoint of the interleaflet triangles by a small, slightly scalloped incision (Figure E2).

3. Implantation of the pulmonary autograft. Normally the proximal autograft implantation suture line follows the scalloped semilunar attachment of the former aortic valve leaflets half the distance up to the commissure, usually starting at the left coronary sinus (Figure E3). The stitches in the autograft (4-0 polyfilament material) are placed directly at or through the attachment of pulmonary leaflets (Figure E4) following a line congruent to that in the aortic root, as shown in Figure E3. The autograft is placed side by side to the aortic root (Figure E5). The inversion technique may cause leaflet distortion. We start with a U-stitch followed by 3 regular single over-and-over stitches, and again the next series starts with a U-stitch (Figure E6). The U-stitches are very practical for later traction and positioning of the autograft into the aortic root. If the diameter of the annulus is more than roughly $25 \mathrm{~mm}$, a 2-0 polytetrafluoroethylene suture (Gore-Tex suture; W. L. Gore \& Associates, Inc, Flagstaff, Ariz) or Dacron strip is integrated in the suture line during tying of the knots. This polytetrafluoroethylene or Dacron strip is held under tension at each suture segment (1 U-stitch, 3 single stitches) so as to fix the annulus diameter or even reduce it (Figure E7). If a polytetrafluoroethylene 2-0 suture is used, both ends of these sutures are placed outside the nadir of the noncoronary cusp and fixed over a Teflon patch. Alternatively, the interleaflet trigone between the noncoronary and left coronary sinus can be plicated by a U-stitch from outside to reduce the size of the annulus. Next, 5-0 polypropylene U-stitches (Prolene; Ethicon, Inc, Somerville, NJ) buttressed with, for example, autologous pericardial pledgets inside and Teflon patches outside, are used to fix the commissures exactly above the former commissures of the aortic valve, trying to lift up the commissures, commonly by about $1 \mathrm{~cm}$ (Figure E8). Only small parts the left and right coronary sinuses of the autograft are excised before the attachment of the autograft sinuses in a subcoronary fashion to the sinuses of the aortic valve with a 5-0 Prolene polypropylene suture starting at the left coronary sinus-always at the most remote point from the surgeon-in a running over-and-over suture technique toward the surgeon. This is followed by the other end of the suture stitched in an inside-outside fashion through 
the wall of the aortic root, up to the commissure between the left and right coronary ostia (Figure E9).

4. Implantation of the pulmonary homograft. In almost all cases a long (up to the bifurcation) pulmonary homograft is used. The muscular tissue of the allograft is excised as much as possible, leaving only 2 or $3 \mathrm{~mm}$ of allogenic myocardium or replacing the complete muscle rim of the allograft by a pericardial or polytetrafluoroethylene strip. Latest investigations show only minor superiority of the pericardial patch, ${ }^{3,11}$ leading to it now being applied only in small-sized homografts. The distal suture line is performed with 5-0 Prolene polypropylene suture whereby the stitches are placed close together to ameliorate constriction by the suture line.
For the proximal anastomosis, 5-0 or 4-0 Prolene polypropylene sutures, depending on the allograft material, are used, with special care not to injure the area of the septal branch where the stitches are placed superficially. The size of the homograft is chosen to be $25 \mathrm{~mm}$ in diameter or larger.

\section{E-References}

E1. Sievers HH, Schmidtke C. A classification system for the bicuspid aortic valve from 304 surgical specimens. J Thorac Cardiovasc Surg. 2007;133: 1226-33.

E2. Notzold A, Scharfschwerdt M, Thiede L, Huppe M, Sievers HH. In-vitro study on the relationship between progressive sinotubular junction dilatation and aortic regurgitation for several stentless aortic valve substitutes. Eur J Cardiothorac Surg. 2005;27:90-3. 


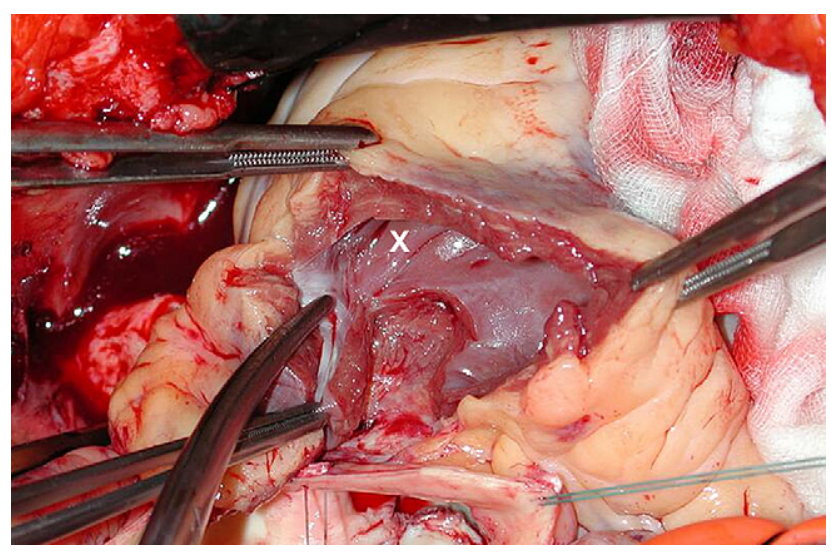

FIGURE E1. Excision of the autograft. Usually a muscle band $(X)$ in the right ventricular outflow tract indicates the location of the septal branches (tip of scissors).

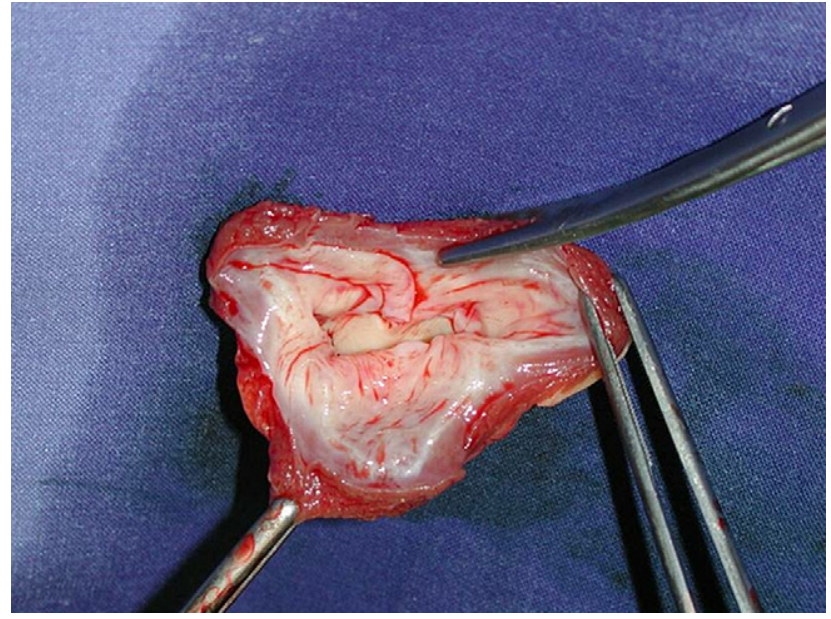

FIGURE E2. Preparation of the autograft. The autograft is trimmed leaving only a 1-2-mm rim of muscular tissue and incising the interleaflet triangle slightly in a scalloped fashion.

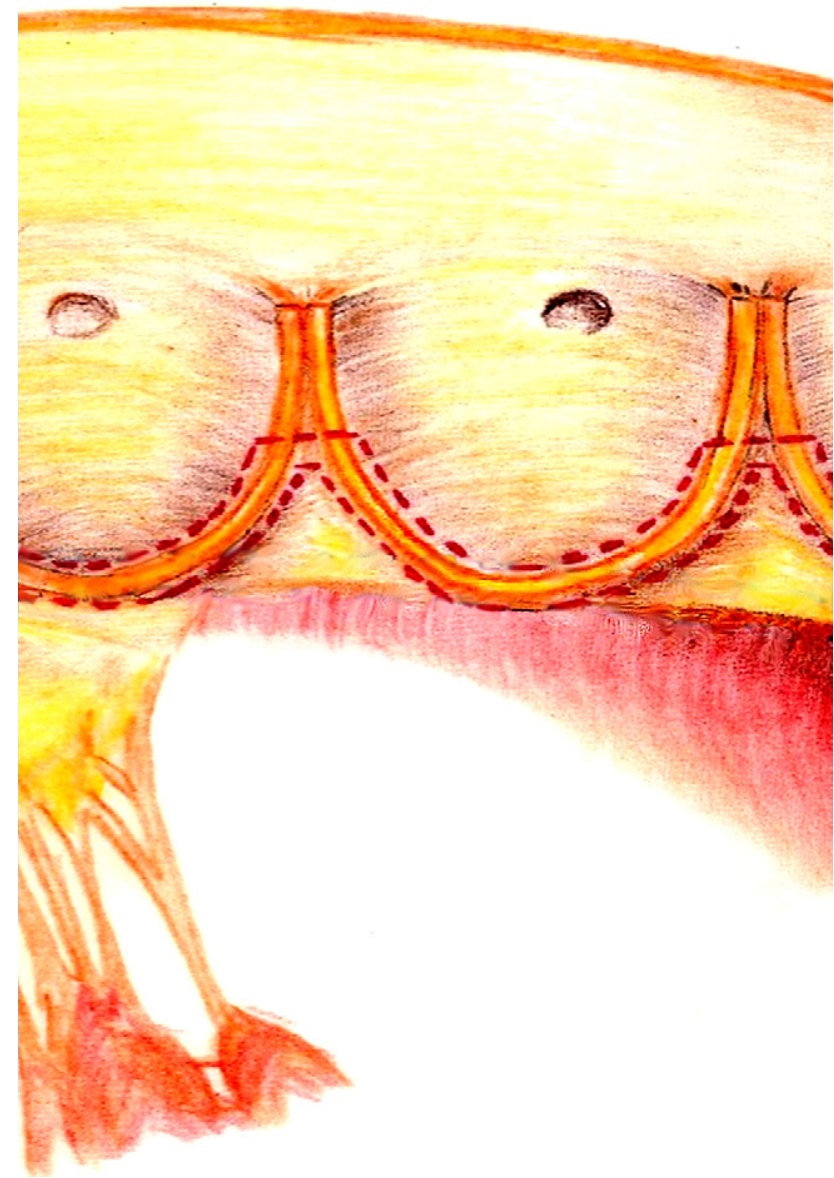

FIGURE E3. Implantation of the autograft. This schematic drawing shows the suture line (broken red lines) following the attachment of the former aortic valve leaflets halfway up to the commissures. 


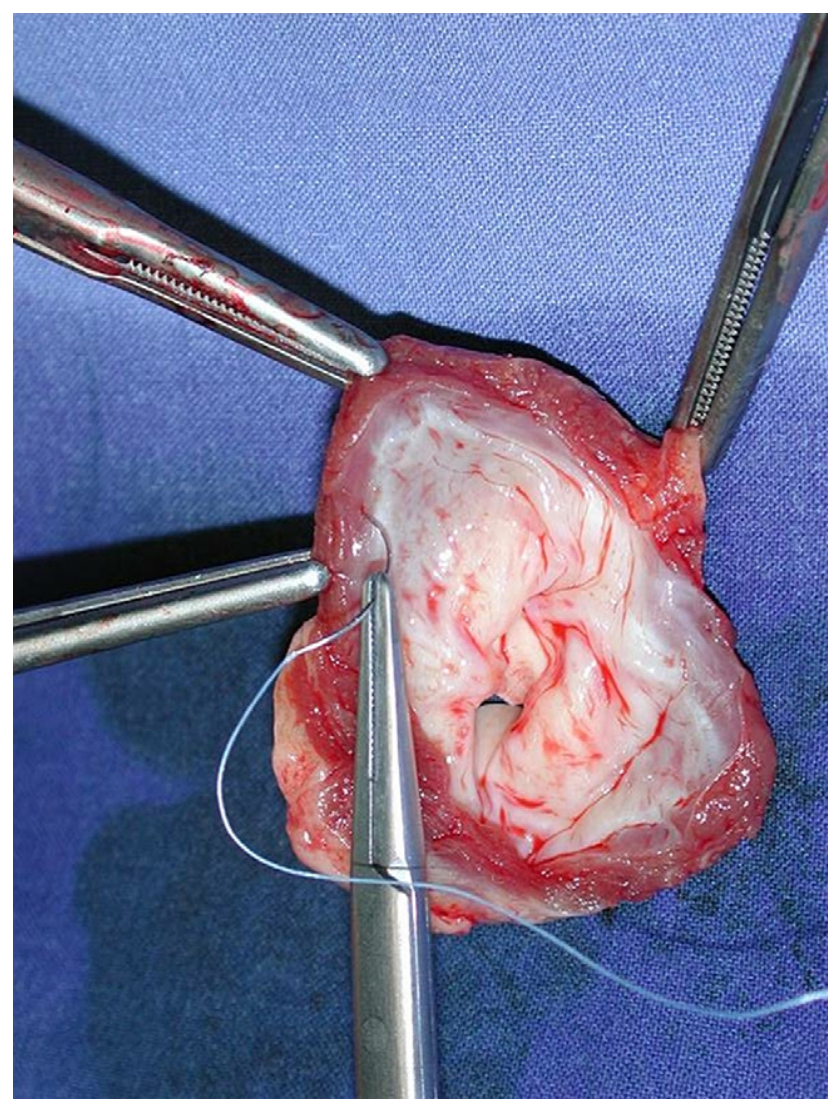

FIGURE E4. Implantation of the autograft. Sutures of the proximal suture line are placed close to the scalloped attachment of the semilunar leaflets of the pulmonary autograft.

\section{Anulus side by side}

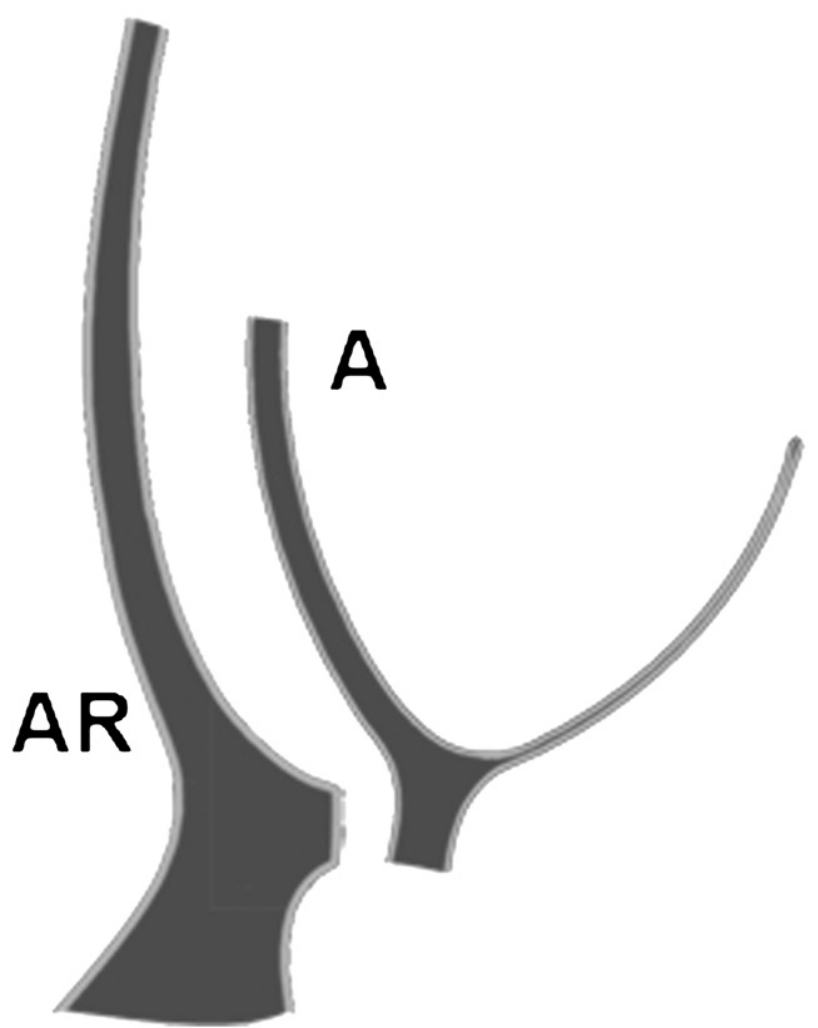

FIGURE E5. Implantation of the autograft. The autograft $(A)$ is sutured side by side to the annulus of the aortic root $(A R)$.

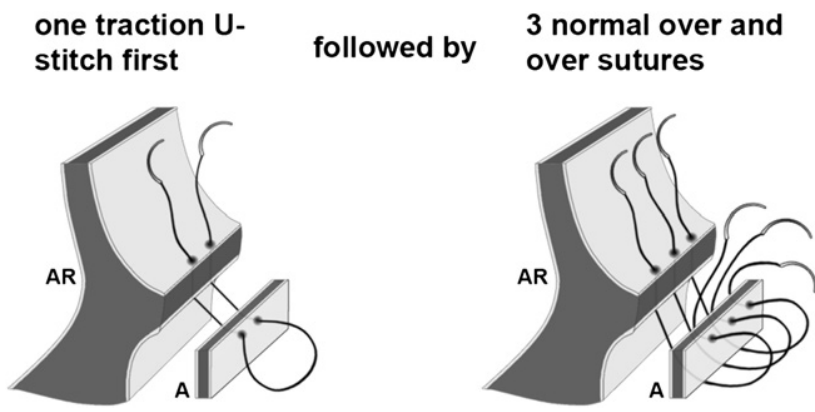

FIGURE E6. Implantation of the autograft. One U-stitch is used first, followed by 3 over-and-over single stitches. This series of sutures is then repeated all around the annulus ( $A$, autograft; $A R$, aortic root). The U-stitches are helpful for traction and positioning the autograft into the root. 


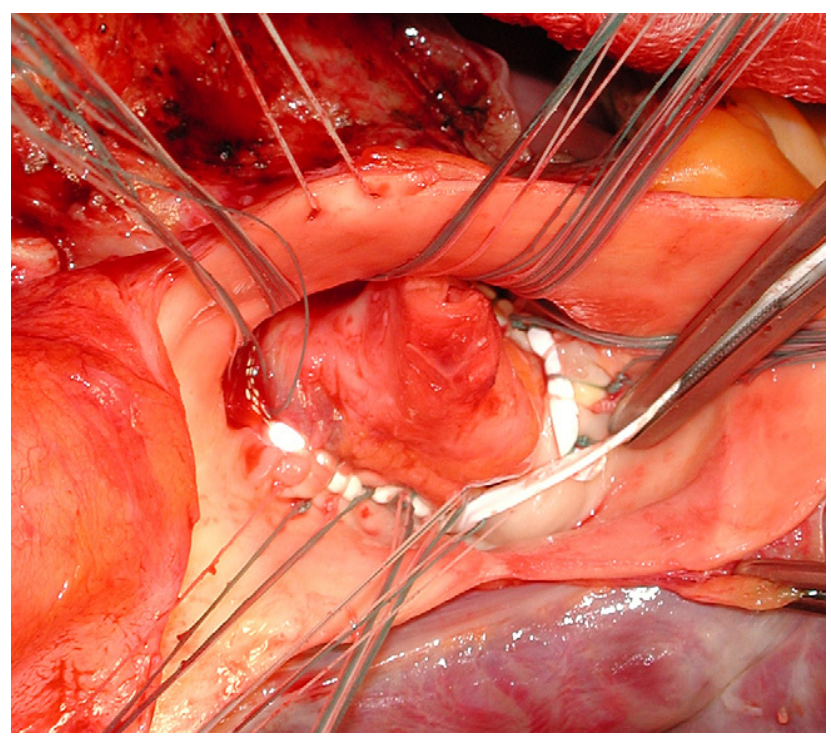

FIGURE E7. Implantation of the autograft. A strip of polytetrafluoroethylene or a 2-0 polytetrafluoroethylene suture is integrated in the proximal suture line to reduce and stabilize a dilated annulus.

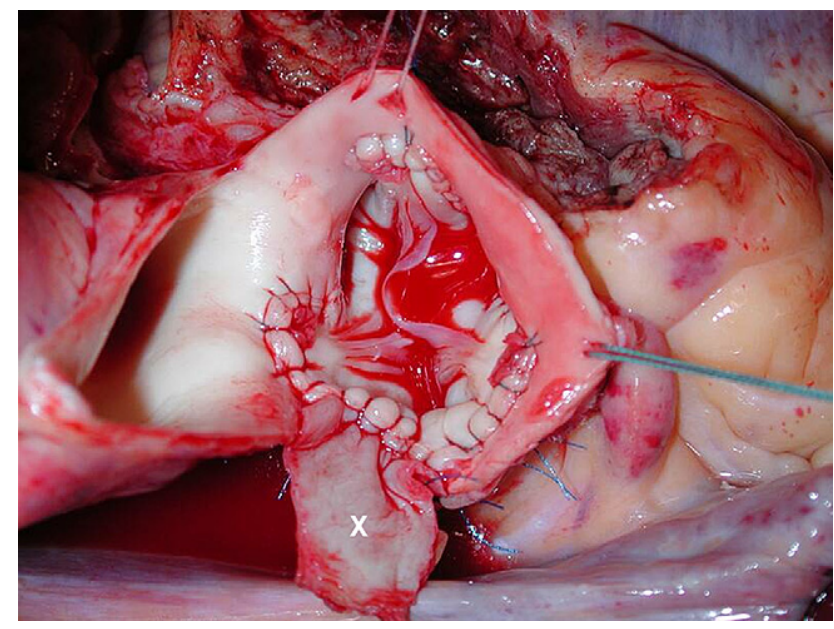

FIGURE E9. Implantation of the autograft. The distal sinus suture line using 5-0 Prolene polypropylene continuously is completed. A pericardial patch $(X)$ is integrated in this case into aortotomy closure line to adjust a narrowed sinotubular junction of the aortic root to the autograft dimensions.

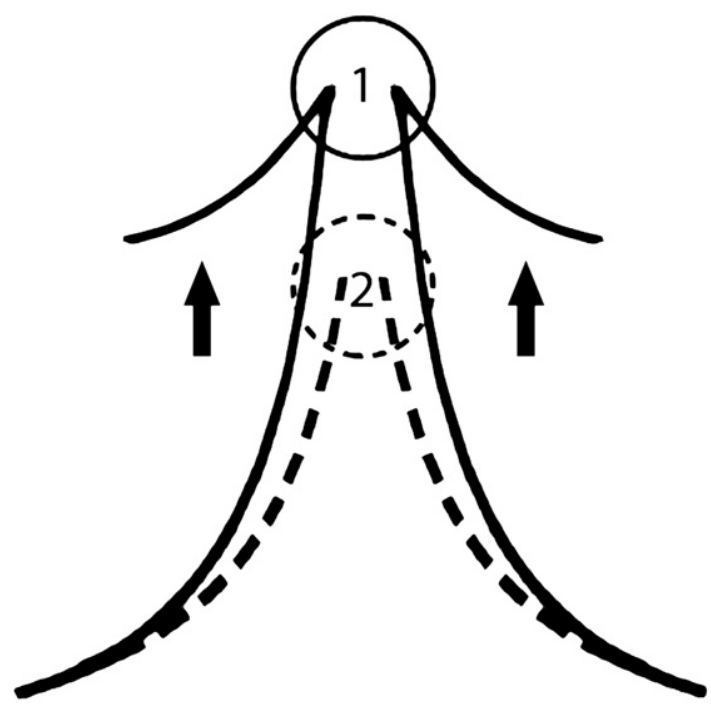

\section{pulmonary autograft}

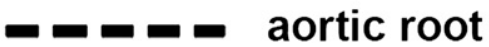

FIGURE E8. Implantation ofthe autograft. The commissure of the autograft (1) is hitched up roughly $1 \mathrm{~cm}$ above the commissure of the corresponding aortic root (2). 